\title{
Influence of Compatibilizer on Blends Degradation During Processing
}

\author{
Walter R. Waldman \\ Universidade Federal de São Carlos, campus Sorocaba \\ Marco-A. De Paoli \\ Instituto de Química, Universidade Estadual de Campinas
}

\begin{abstract}
The thermomechanical degradation of blends made from polypropylene and polystyrene, with or without compatibilizer, was studied using an internal mixer coupled to a torque rheometer. The blends processed without compatibilizer presented regular and expected results regarding torque reduction, with evidence of chain scission. The blends processed with the block copolymer of styrene and butadiene, SBS, as a compatibilizer presented unchanged or less reduced variation on torque values during processing. The extraction of stabilizers from the compatibilizer before processing did not affect the results. The compatibilizer concentration in the blends was varied, with its influence still being observed in concentrations as low as 0.03 parts per hundred. Similar results were obtained in an experiment comparing the performance of a primary commercial anti-oxidant, Irganox 1076, and the compatibilizer SBS. Therefore, the compatibilizer can be considered as a processing aid agent with positive influence on avoiding thermomechanical degradation.
\end{abstract}

Keywords: Blend, thermomechanical degradation, polypropylene, polystyrene, poly(styrene-co-butadyene-co-styrene), SBS.

\section{Introduction}

The thermomechanical degradation of polymer blends has been studied in the last three decades ${ }^{[1-7]}$, however, a large number of research topics remain untouched due to the variety of interactions that can occur between the blend components. These interactions may generate antagonism or synergism between the degradation mechanisms, depending on composition ${ }^{[8-11]}$, the kind of degradation ${ }^{[12,13]}$ or blend miscibility ${ }^{[14-17]}$. The interactions between the blend domains may occur with different proportions between two extremes: pro-degrading species generated in a domain migrating to another domain, with changes in degradation kinetics, and with the different domains degrading independently, without variation in degradation kinetics of the blend components ${ }^{[18]}$.

During melt processing, the polymeric material is heated and sheared to produce an adequate flow. At this point the polymer chain dissipates the mechanical shear forces by relaxation processes, common to viscoelastic materials. When a relaxation process is obstructed by the material viscosity, by entanglements or by crosslinking, covalent chemical bonds may be broken. The higher the time needed for the relaxation processes to occur, the higher is the probability to break bonds in the polymeric chain under these conditions ${ }^{[19,20]}$. Because of that, increasing the material viscosity may influence, in a direct proportional way, chain scissions during the application of mechanical energy ${ }^{[21]}$. The chain scission, mainly homolytic, plays a significant role on polymer degradation. Homolytic scission may occur mainly in two sites: backbone, causing decrease of molar mass, and in terminal pendent groups. Thermomechanical degradation ${ }^{[22-24]}$ begins, generally, with the former option, homolytic scission of backbone $\mathrm{C}-\mathrm{C}$ covalent bonds, generating free radicals (Figure 1a). These free radicals may undergo some chemical reactions, like disproportionation, causing chain scission, lowering the molar mass and increasing the melt flow index (Figure 1b), or crosslinking, causing an increase of molar mass and lowering the melt flow index (Figure 1c).

Depending on the competition between these processes, the result can be either molar mass reduction or its increase after degradation. Whether chain scission or crosslinking occurs depends on the polymer under processing and the processing parameters, like e.g. temperature ${ }^{[25]}$. Beyond that, the process can be dependent of initial molar mass ${ }^{[24,26]}$ or not ${ }^{[27]}$. Besides the competition between these degradation processes, radical mobility becomes more important in thermomechanical degradation because the polymers are in the molten state, therefore with higher degrees of freedom.

Free radicals play an important role in the thermomechanical degradation processes. The macroradicals generated in the degradation of polypropylene, PP, and polystyrene, PS, were studied by Shyichuk et al. ${ }^{[28]}$. They simulated the electron density of the macroradicals and determined their relative stability, concluding that PS macroradicals display a larger spin delocalization and are more stable than PP macroradicals.

One of the methods used to evaluate the reduction or increase of the molar mass after thermomechanical degradation is measurement of the torque variation as a function of the processing time, in a torque rheometer coupled to an internal mixer ${ }^{[29-35]}$. Under constant conditions of temperature and rotation speed of the rotors, the variation of the torque is an indirect measure of the molar mass variation and, after loading of the polymers, there are three possibilities:

1- Increase of the torque: higher resistance to the movement of the rotors means crosslinking reactions and consequent increase of molar mass and viscosity;

2- Reduction of the torque: lower resistance to the movement of the rotors means chain scission reactions and consequent reduction of molar mass and viscosity;

3- Maintenance of the torque: constant torque could mean no significant thermomechanical degradation or reactions of scission and crosslinking occurring simultaneously ${ }^{[33]}$.

These three possibilities may happen with polymer blends during their thermomechanical degradation, depending on the competition between the processes of their components and the interactions among them.

Another factor that can influence thermomechanical degradation is the presence of oxygen in the melt from spaces between the pellets or inside the processing equipment. The molecular oxygen can diffuse into the polymeric matrix and react with the macroalkyl radicals, generating peroxy radicals and starting the autocatalytic propagation ${ }^{[36]}$ shown in Figure 2. 


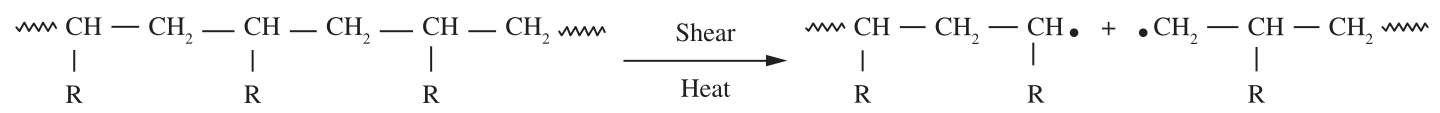

(a)

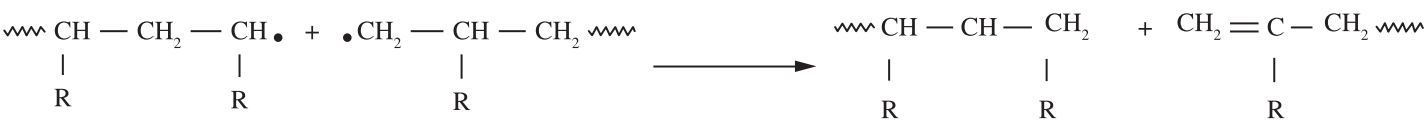

(b)

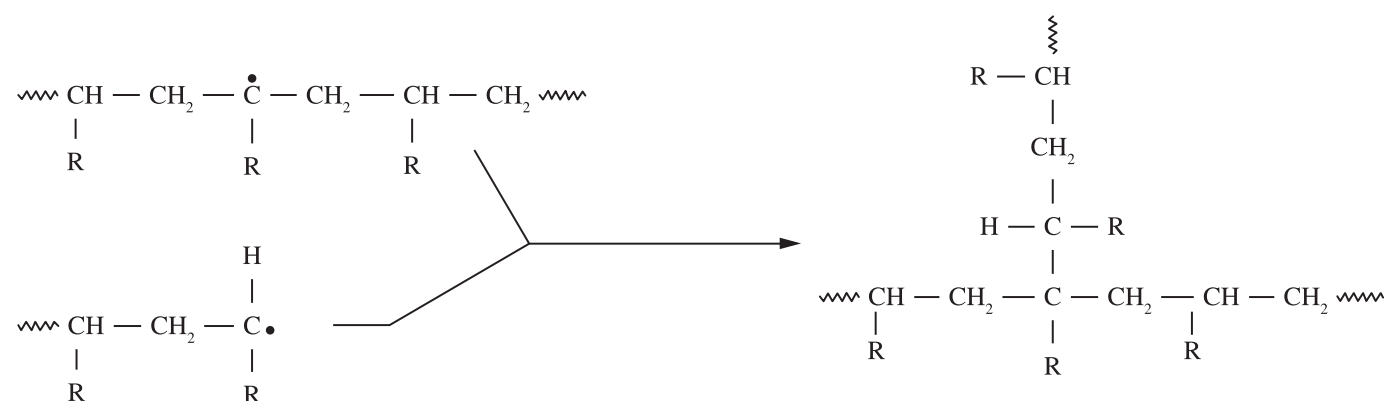

(c)

Figure 1. Representation of a) C-C covalent bond scission due to shear and/or heat, b) disporportionation reaction of an alkyl macroradical, and c) crosslinking reaction between alkyl macroradicals.

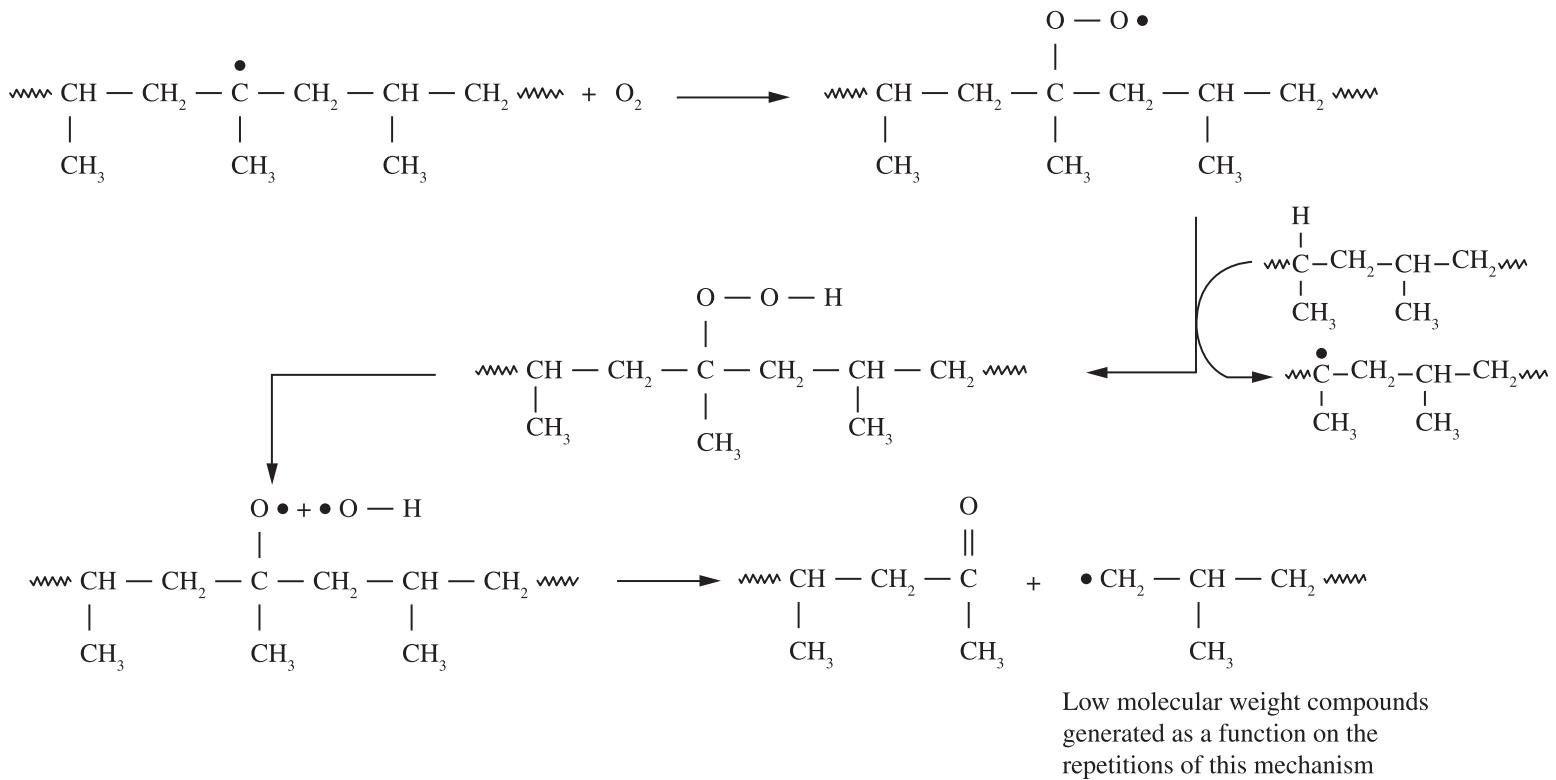

Figure 2. Representation of the reaction of the free radicals generated in the thermomechanical degradation of polypropylene with oxygen and subsequent reactions.

The participation of oxygen in thermomechanical degradation was previously studied for PP and low density polyethylene, LDPE, in experiments using an internal mixer coupled to a torque rheometer, comparing the results of experiments having air in the free volume of the chamber or using the chamber after purging with argon ${ }^{[37]}$. An invariable torque was observed for PP and LDPE processed for 30 minutes under argon. In the presence of oxygen, a variation of torque was observed for the same materials. Another experiment studying the role of oxygen in the thermomechanical degradation of HDPE synthesized with different catalysts was done by Pinheiro et al. ${ }^{[38]}$. An invariable torque value was also observed for processing in the absence of oxygen in the mixing chamber.

Polymers can be mixed presenting phase separation and, therefore, are not thermodynamically miscible. Despite this limitation, we can find a number of applications for their blends, partly because the gain of stability by the addition of substances called compatibilizers. Compatibilizers interact with both components of a blend, reducing the interfacial tension and increasing the interaction of different domains ${ }^{[39]}$. SBS is a copolymer with these characteristics and act as compatibilizer in blends, such as those studied in this work ${ }^{[40]}$. Polystyrene and postconsumer polyethylene can form blends of commercial interest with the commercial use of copolymers of styrene-butadiene multiblock copolymer, SBS, or styrene-(ethyene-co-butylene)-styrene, SEBS, for the composition of blends ${ }^{[41]}$. Blends of polypropylene and polystyrene are immiscible and may be compatibilized by copolymers, like SBS or SEBS reducing the domain size of the dispersed phase ${ }^{[42-47]}$. The compatibilization of blends made of PP and PS has been studied, making these blends technologically useful ${ }^{[48-51]}$. 
This work aims to study the effect of the presence of the SBS compatibilizer on torque behavior of polypropylene and polystyrene blends during processing in an internal mixer coupled to a torque rheometer.

\section{Experimental}

The isotactic polypropylene (PP) used was H503 in pellets (density $0.91 \mathrm{~g} \mathrm{~cm}^{-3}$ and MFI $3.4 \mathrm{~g} 10 \mathrm{~min} / A S T M$ D 1238), as supplied by Braskem (Triunfo). The polystyrene (PS) used was PSPG EDN 88-G in pellets (density $1.05 \mathrm{~g} \mathrm{~cm}^{-3}$ and MFI $19.3 \mathrm{~g}$ $10 \mathrm{~min} / \mathrm{ASTM}$ D 1238), as supplied by EDN-Poliestireno do Sul (Camaçari). The styrene-butadiene-styrene block copolymer (SBS) used was TR-1061 in pellets, as supplied by Petroflex, Industria e Comércio S.A. (Triunfo). All samples contained the usual stabilization package of the producer.

The purification of SBS was made by dissolution in tetrahydrofurane ( $5 \mathrm{wt}$. (\%) of SBS in relation to THF) and coagulation in water in the ratio of 1:20, with three repetitions of the procedure. The stabilizer used in the experiments of thermomechanical degradation, for efficiency comparison with SBS, was Irganox 1076 (Octadecyl 3,5-di-(tert)-butyl-4-hydroxyhydrocinnamate), supplied by Ciba Especialidades Químicas S.A. (São Paulo).

The thermomechanical degradation experiments were done in an internal mixer with two counter-rotating rotors coupled to a HAAKE Rheocord 90 Torque Rheometer, at $230{ }^{\circ} \mathrm{C}, 40 \mathrm{rpm}$ and 90 minutes. SBS was used as a compatibilizer in the 0.03 to $3.00 \mathrm{phr}$ range $(\mathrm{phr}=$ parts per hundred of resin). The processing was done with locked feeder in rheometer. All experiments were done in duplicate and the presented curves are their average.

The melt flow indexes of the blend components were determined using a DSM Plastometer, model MI-3.

\section{Results and Discussion}

Thermomechanical degradation was studied by following the torque changes during mixing. Prior to feeding, the mixer was pre-heated and the rotor speed was adjusted. After loading the mixer with the cold pellets and locking the feeder, all samples presented a torque peak and temperature decay, followed by torque and temperature stabilization. The curves reported in Figures 3 and 4 are related to the torque variation after this stabilization process.

In Figure 3 we compare the torque variation as a function of time for homopolymers PP and PS and for blends with 15, 30 and 45 wt. (\%) of PS. Torque values for blends were roughly between the torque values for PP and PS. We observe for all cases a torque reduction as a function of processing time, as expected due to thermomechanical degradation of polypropylene $e^{[52]}$ and polystyrene ${ }^{[27,53]}$. The values of torque after loading (10 minutes), the values of torque in 90 minutes and the variation between 10 and 90 minutes of experiment are summarized in Table 1.

Despite the apparent higher degradation of polystyrene, when compared with polypropylene (Table 1) it is necessary to take into account the fluidity of the material under the same conditions, because the ASTM D 1238 standard determines different conditions for measurement of melt flow index, MFI, for polystyrene and polypropylene. In order to make an adequate comparison, the measurement of the MFI of both polymers was made at the same conditions to determine the parameters of flow at the same temperature $\left(230{ }^{\circ} \mathrm{C}\right)$ and under the same load $(2.16 \mathrm{~kg})$, using the DSM plastometer. Results of melt flow index, MFI, under the same conditions showed a higher value for PS $\left(20.3 \pm 0.3 \mathrm{~g} 10 \mathrm{~min}^{-1}\right)$ in comparison to PP $\left(16.5 \pm 0.5 \mathrm{~g} 10 \mathrm{~min}^{-1}\right)$. The different MFI for the blend components partially precludes their comparison in relation to torque reduction as a function of processing time. Due to this, in this work, only blends with the same homopolymer composition were compared, changing the presence or absence of SBS as compatibilizer.

In Figure 4 are presented the results for blends processed inside the mixer with $3 \mathrm{phr}$ of SBS as compatibilizer. For PP/PS blends the addition of SBS improves the interaction between the domains, acting as a compatibilizer ${ }^{[45]}$. The blends with SBS $3 \mathrm{phr}$ presented lower torque variation as a function of time (Figure 4 and Table 1), in comparison to the blends processed without SBS, indicating that the presence of the compatibilizer markedly affects

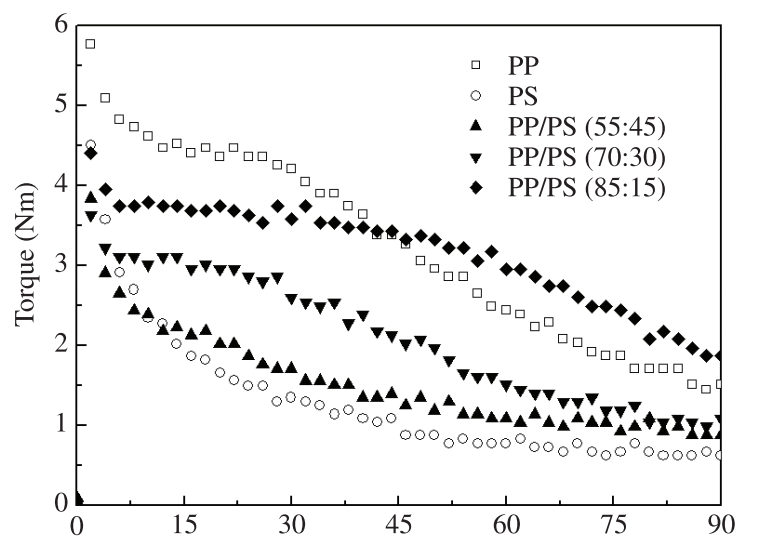

Figure 3. Variation of torque as a function of processing time in an internal mixer coupled to a torque rheometer for PP, PS and their blends without compatibilizer.

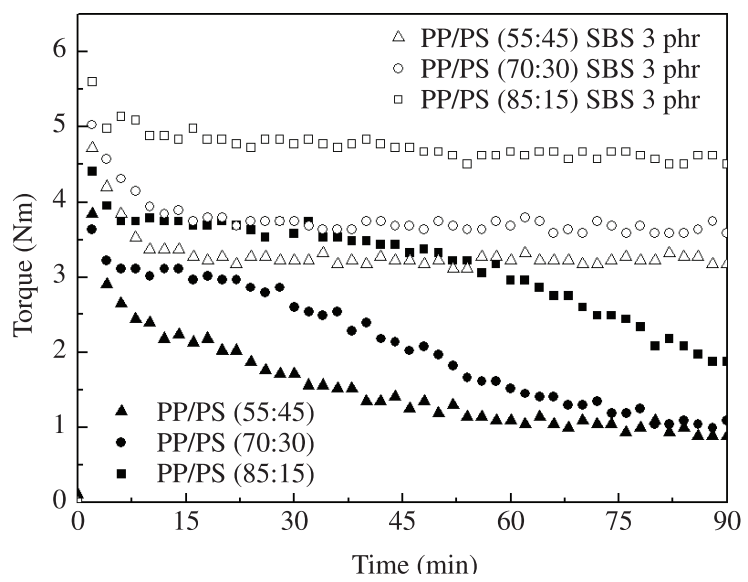

Figure 4. Comparison of torque variation as a function of processing time in an internal mixer coupled to a torque rheometer for PP/PS blends without and with 3 phr of SBS compatibilizer.

Table 1. Values of torque at the beginning and at the end of processing and its percent variation.

\begin{tabular}{cccc}
\hline Material & $\begin{array}{c}\text { Torque after } \\
\text { 10 } \mathbf{m i n}(\mathbf{N . m})\end{array}$ & $\begin{array}{c}\text { Torque after } \\
\mathbf{9 0} \text { min (N.m) }\end{array}$ & $\begin{array}{c}\text { Percent torque } \\
\text { reduction }\end{array}$ \\
\hline PP & 4.6 & 1.5 & 67 \\
PS & 2.4 & 0.6 & 75 \\
PP/PS (85:15) & 3.8 & 1.9 & 50 \\
PP/PS (70:30) & 3.1 & 1.0 & 68 \\
PP/PS (55:45) & 2.4 & 0.9 & 63 \\
PP/PS (85:15) & 4.9 & 4.5 & 8 \\
SBS 3 phr & & & \\
PP/PS (70:30) & 3.9 & 3.6 & \\
SBS 3 phr & & & 6 \\
PP/PS (55:45) & 3.4 & 3.2 & \\
SBS 3 phr & & &
\end{tabular}




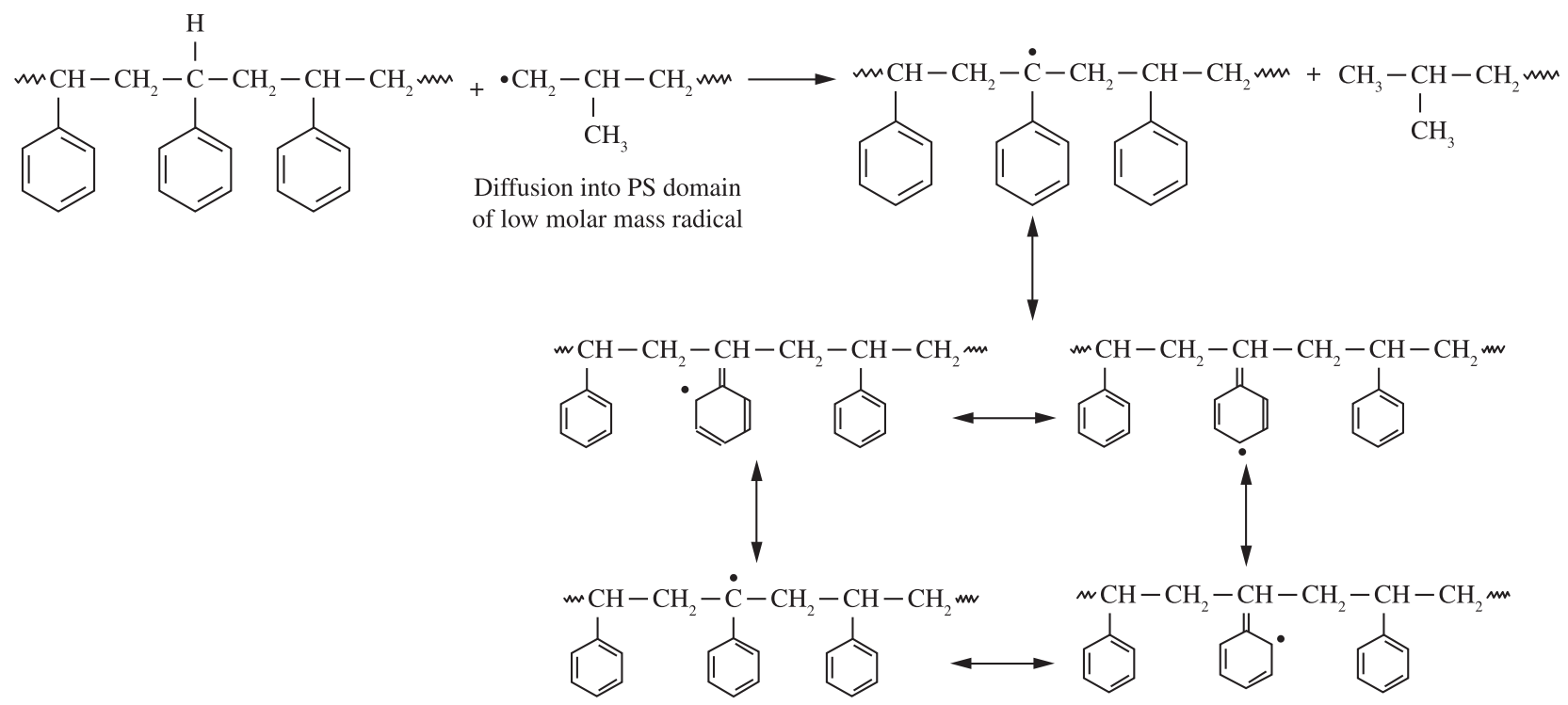

Figure 5. Representation of the migration and interaction between radical species in the interface of PP and PS domains.

the thermomechanical degradation process. The torque variation for blends processed without SBS was between 50 and $68 \%$, while it was drastically lowered to 6 and $8 \%$ when using 3 phr of SBS, for all blend compositions.

From the results shown in Figure 4, we can deduce that there is a compatibilizing effect of SBS on the thermomechanical behavior of the blend during processing in the torque rheometer. This effect may be mainly due to two hypotheses: the effect of SBS as compatibilizer or the stabilizing effect of any additive in the formulation of SBS. Concerning the first hypothesis, the compatibilizer could act by promoting the synergistic interaction between the domains and their degradative mechanisms, i.e., promoting the interaction between domains and consequently the migration and stabilizing or deactivating the radicalar species after migration from one domain to another. Additionally to the interaction between domains, the plasticizing effect of SBS increases the free volume and thus minimizes the effect of shear in the torque variations. The second hypothesis will be discussed below.

The synergistic effect can be better understood with the aid of the scheme presented in Figure 5, where it is suggested that the migration, from PP to PS domain, of low molar mass free radicals (for instance, the radicals generated in Figure 2), may contribute to this stabilization effect. Since radical migration depends on the interfacial area between the domains, we may conclude that the compatibilizer increases this interaction by increasing the interfacial area. The low molar mass radicals generated in the PP domain can be deactivated by hydrogen abstraction in the PS domains, generating a less reactive aromatic radical species in these PS domains, because aromatic radicals are stabilized by resonance within the aromatic ring ${ }^{[28]}$.

Concerning the second hypothesis on the stabilizing effect resulting from additives from SBS, further processing was done with purified SBS and the PP/PS (85:15) blend (Figure 6). There was no significant variation in the stabilizing effect observed previously for the compatibilized blends. There was no observed significant change in the torque curve variation as a function of time for the blend with the SBS used as received and with the purified SBS. Thus, we have eliminated the hypothesis of influence of SBS additives.

After the assessment of the SBS effect in the PP/PS blend processing, we made a study to establish the influence of the amount of SBS in achieving this effect. To test this influence, we studied the effect of the variation of concentration of SBS in the blend, Figure 7.

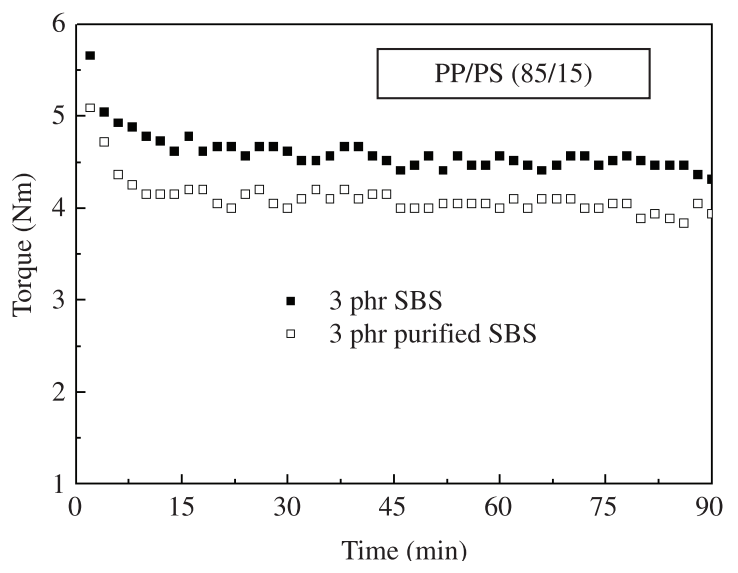

Figure 6. Variation of torque as a function of processing time for a PP/PS $(85: 15)$ blend with purified and as received SBS.

For blends with 3.0 and $0.6 \mathrm{phr}$ of SBS no torque variation was observed. When we reduced the concentration of SBS to $0.03 \mathrm{phr}$ we observe the beginning of torque variation only for times longer than 65 minutes for the blends with 15 and 45 wt. (\%) of PS. For the blend with $30 \mathrm{wt}$. (\%) of PS, no significant variation of torque is observed, not even for the lowest SBS content. We can conclude that, for the three studied blend compositions, the compatibilizer SBS, in three concentrations studied, exerts the effect of stabilizing the torque during processing. It is interesting to note that the lowest concentration used, $0.03 \mathrm{phr}$, is equivalent to a half pellet of SBS.

Finally, to compare the stabilizing effect exerted by SBS with a commercial stabilizer, we processed the blend PP/PS 70:30 with a hindered phenol additive, Irganox $1076^{\circledR}$, at 0.05 and $0.4 \mathrm{phr}$ concentrations. Hindered phenols are free-radical suppressors and should prevent thermomechanical degradation. The obtained results, with relation to the torque variation as a function of time, for the concentration of $0.05 \mathrm{phr}$ of Irganox $1076^{\circledR}$, were similar to those obtained with the lowest concentrations of SBS, 0.03 and 0.06 phr, Figure 8.

A qualitative evidence of the stabilizing effect of the SBS compatibilizer is the lack of yellowing in the blend processed in its presence. In Figure 9 we compare the samples processed with (left) and without (right) SBS, showing the remarkable yellowing of the sample processed without SBS, which is also an indication of degradation ${ }^{[54,55]}$. 

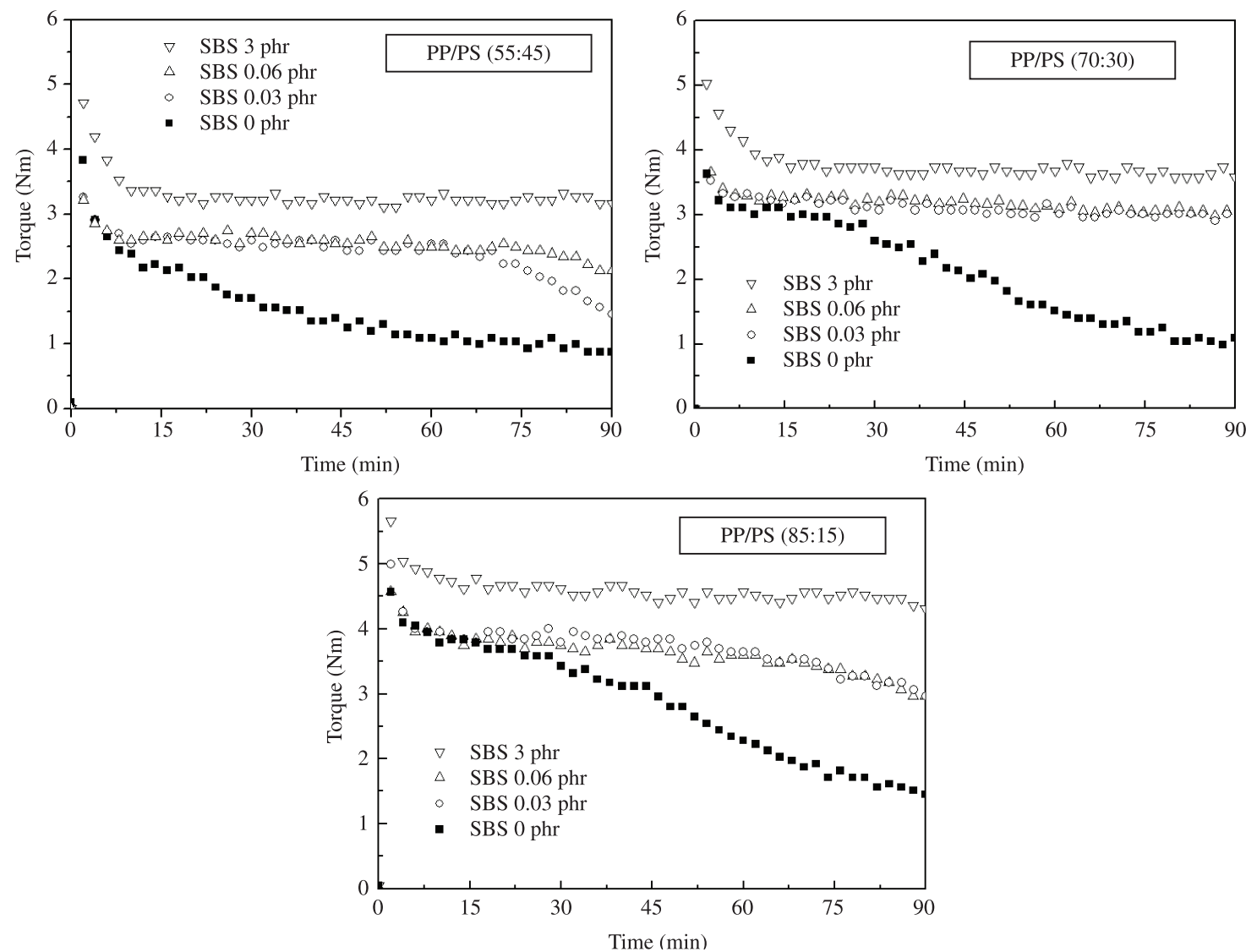

Figure 7. Torque variation curves as a function of time for the blends with 15, 30 and 45 wt. (\%) PS with different concentrations of SBS.

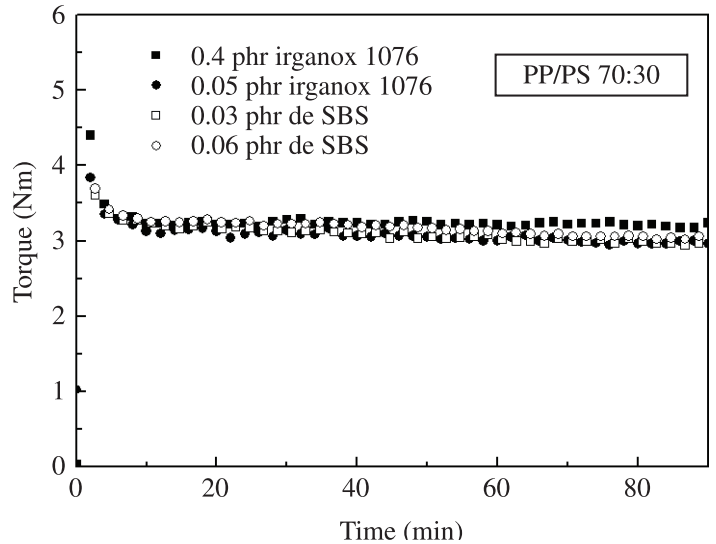

Figure 8. Torque variation curves as a function of time for the blend PP/PS (70:30) with SBS and with Irganox $1076^{\circledR}$.

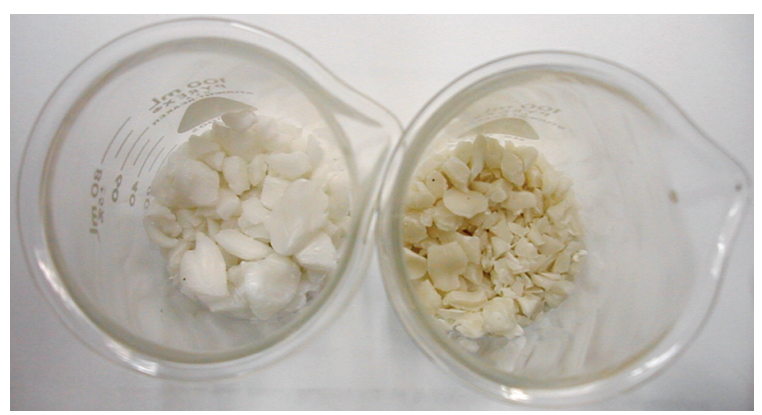

Figure 9. Photography of PP/PS (85:15) blends processed without compatibilizer, right side, and processed with $0.03 \mathrm{phr}$ of the SBS compatibilizer, left side.

\section{Conclusions}

The thermomechanical behavior of PP/PS blends is shown by torque reduction as a function of processing time. SBS compatibilizer has a significant stabilizing effect on the thermomechanical degradation of these blends, lowering the torque variation of the blends as a function of processing time. The efficiency of the compatibilizer in preventing degradation during the processing of the blends was comparable to the efficiency of a commercial hindered phenol antioxidant. The SBS concentration presented linear stabilizing effect behavior. Finally, the results showed that the chemical interaction between the different domains of a blend must be considered when we need to determine the stability towards processing.

\section{Acknowledgements}

The authors thank FAPESP for a fellowship (WRW, 97/06666-6) and financial support (2010/17804-7). MAP also acknowledges $\mathrm{CNPq}$ for a research fellowship and a grant.

\section{References}

1. La Mantia, F. P. - Mat. Chem. Phys., 16, p.115 (1987). http://dx.doi. org/10.1016/0254-0584(87)90023-X

2. La Mantia, F. P. \& Nocilla, M. A. - Polym. Degrad. Stab., 17, p. 279 (1987). http://dx.doi.org/10.1016/0141-3910(87)90088-7

3. La Mantia, F. P. \& Valenza, A. - Angew. Makromol. Chem., 216, p.45 (1994). http://dx.doi.org/10.1002/apmc.1994.052160104

4. La Mantia, F. P.; Valenza, A. \& Acierno, D. - Polym. Degrad. Stab., 13, p.1 (1985). http://dx.doi.org/10.1016/0141-3910(85)90130-2 
5. Khatua, B. B. \& Das, C. K. - J. Thermal Analysis and Calorimetry, 63, p.565 (2001). http://dx.doi.org/10.1023/A:1010158324665

6. Maity, M.; Khatua, B. B. \& Das, C. K. - Polym. Degrad. Stab., 70, p.263 (2000). http://dx.doi.org/10.1016/S0141-3910(00)00125-7

7. Paukszta, D. \& Borysiak, S. - Polimery, 54, p.126 (2009).

8. Kaczmarek, H. - Eur. Polym. J., 31, p.1175 (1995). http://dx.doi. org/10.1016/0014-3057(95)00095-X

9. Klaric, I.; Roje, U. \& Bravar, M. - J. Appl. Polym. Sci., 61, p.1123 (1996) http://dx.doi.org/10.1002/(SICI)1097-4628(19960815)61:7<11 23::AID-APP8>3.0.CO;2-O

10. Deuri, A. S.; Adhikary, A. \& Mukhopadhyay, R. - Polym. Degrad. Stab., 41, p.53 (1993).

11. Mohamed, N. A. \& Sabaa, M. W. - Eur. Polym. J., 35, p.1731 (1999). http://dx.doi.org/10.1016/S0014-3057(98)00257-2

12. Pospísil, J.; Horak, Z.; Krulis, Z.; Nespurek, S. \& Kuroda, S. - Polym. Degrad. Stab., 65, p.405 (1999).

13. Waldman, W. R. \& De Paoli, M. A. - Polym. Degrad. Stab., 93, p.273 (2008). http://dx.doi.org/10.1016/j.polymdegradstab.2007.09.003

14. Chiantore, O.; Trossarelli, L. \& Lazzari, M. - Polymer, 39, p.2777 (1998). http://dx.doi.org/10.1016/S0032-3861(97)00636-8

15. Kaczmarek, H. - Polymer, 37, p.189 (1996). http://dx.doi. org/10.1016/0032-3861(96)81086-X

16. Lizymol, P. P. \& Thomas, S. - Polym. Degrad. Stab., 41, p.59 (1993). http://dx.doi.org/10.1016/0141-3910(93)90061-M

17. Rincon, A. \& McNeill, I. C. - Polym. Degrad. Stab., 40, p.343 (1993). http://dx.doi.org/10.1016/0141-3910(93)90140-E

18. Bate, D. M. \& Lehrle, R. S. - Polym. Degrad. Stab., 62, p.57 (1998). http://dx.doi.org/10.1016/S0141-3910(97)00261-9

19. Schnabel, W. - "Polymer degradation, principles and practical applications", Hanser International, Munich (1981).

20. De Paoli, M. A. - "Degradação e Estabilização de Polímeros", Artliber, São Paulo (2009).

21. La Mantia, F. P. - Angew. Makromol. Chem., 216, p.45 (1994). http:// dx.doi.org/10.1002/apmc.1994.052160104

22. Hinsken, H.; Moss, S.; Pauquet, J. R. \& Zweifel, H. - Polym. Degrad. Stab., 34, p.279 (1991). http://dx.doi.org/10.1016/01413910(91)90123-9

23. Moss, S. \& Zweifel, H. - Polym. Degrad. Stab., 25, p.217 (1989). http:// dx.doi.org/10.1016/S0141-3910(89)81009-2

24. Pinheiro, L. A.; Chinelatto, M. A. \& Canevarolo, S. V. - Polym. Degrad. Stab., 86, p.445 (2004). http://dx.doi.org/10.1016/j. polymdegradstab.2004.05.016

25. Cáceres, C. A. \& Canevarolo, S. V. - Polímeros, 19, p.79 (2009). http:// dx.doi.org/10.1590/S0104-14282009000100017

26. Canevarolo, S. V. - Polym. Degrad. Stab., 70, p.71 (2000). http://dx.doi. org/10.1016/S0141-3910(00)00090-2

27. Cáceres, C. A. \& Canevarolo, S. V. - Polímeros, 18, p.348 (2008). http://dx.doi.org/10.1590/S0104-14282008000400015

28. Shyichuk, A.; Melnyk, D. \& White, J. R. - J. Polym. Sci. A: Polym. Chem., 41, p.1070 (2003). http://dx.doi.org/10.1002/pola.10645

29. Gugumus, F. - Polym. Degrad. Stab., 66, p.161 (1999). http://dx.doi. org/10.1016/S0141-3910(99)00077-4

30. Gugumus, F. - Polym. Degrad. Stab., 67, p.35 (2000). http://dx.doi. org/10.1016/S0141-3910(99)00115-9

31. Gugumus, F. - Polym. Degrad. Stab., 68, p.21 (2000). http://dx.doi. org/10.1016/S0141-3910(99)00163-9
32. Hussein, I. A.; Ho, K.; Goyal, S. K.; Karbashewski, E. \& Williams, M. C. - Polym. Degrad. Stab., 68, p.381 (2000). http://dx.doi.org/10.1016/ S0141-3910(00)00022-7

33. Waldman, W. R. \& De Paoli, M. A. - Polym. Degrad. Stab., 60, p.301 (1998) http://dx.doi.org/10.1016/S0141-3910(97)00083-9

34. Wang, X.; Yu, W.; Nie, Q.; Guo, Y. \& Du, J. - J. Appl. Polym. Sci., 121, p.1220 (2011). http://dx.doi.org/10.1002/app.33795

35. Wang, X.; Chen, X.; Yu, W.; Ji, Y.; Hu, X. \& Xu, J. - J. Appl. Polym. Sci., 105, p.1316 (2007). http://dx.doi.org/10.1002/app.26015

36. Gijsman, P. - e-Polymers, article number 065 (2008).

37. Scott, G. - "Developments in polymer stabilization", v.5, Applied Science Publishers, London (1982).

38. Pinheiro, L. A.; Chinelatto, M. A. \& Canevarolo, S. V. - Polym. Degrad. Stab., 91, p.2324 (2006). http://dx.doi.org/10.1016/j. polymdegradstab.2006.04.005

39. Work, W. J.; Horie, K.; Hess, M. \& Stepto, R. F. T. - Pure and Applied Chemistry, 76, p.1985 (2004). http://dx.doi.org/10.1351/ pac200476111985

40. Fernandes L. L.; Freitas, C. A.; Demarquette, N. R. \& Fechin, G. J. M. - J. Appl. Polym. Sci., 120, p.770 (2011) http://dx.doi.org/10.1002/ app.33096

41. Perez, I. S. B.; Manrich, S. \& Manrich, S. - Polímeros, 18, p.207 (2008). http://dx.doi.org/10.1590/S0104-14282008000300005

42. Radonjic, G.; Musil, V. \& Smit, I. - J. Appl. Polym. Sci., 69, p.2625 (1998). http://dx.doi.org/10.1002/(SICI)1097-4628(19980926)69:13< 2625::AID-APP13>3.0.CO;2-T

43. Smit, I. \& Radonjic, G. - Polym. Eng. Sci., 40, p.2144 (2000).

44. Smit, I.; Radonjic, G. \& Hlavata, D. - Eur. Polym. J., 40, p.1433 (2004).

45. Macaúbas, P. H. P. \& Demarquette, N. R. - Polymer, 42, p.2543 (2001). http://dx.doi.org/10.1016/S0032-3861(00)00655-8

46. Brostow, W.; Grguric, T. H.; Olea-Mejia, O.; Rek, V. \& Unni, J. - e-Polymers, article number 033 (2008).

47. Fortelny, I. \& Michalkova, D. - Plast. Rubber Compos. Process. Appl., 27, p.53 (1998).

48. Li, Y. Y.; Hu, S. W. \& Sheng, J. - Eur. Polym. J., 43, p.561 (2007). http://dx.doi.org/10.1016/j.eurpolymj.2006.10.018

49. Wang, Y.; Xiao, Y.; Zhang, Q.; Gao, X. L. \& Fu, Q. - Polymer, 44 p.1469 (2003). http://dx.doi.org/10.1016/S0032-3861(03)00011-9

50. Raghu, P.; Nere, C. K. \& Jagtap, R. N. - J. Appl. Polym. Sci., 88, p.266 (2003). http://dx.doi.org/10.1002/app.11677

51. Li, Y. Y.; Wang, Y.; Li, W. Q. \& Sheng, J. - J. Appl. Polym. Sci., 103, p.365 (2007). http://dx.doi.org/10.1002/app.24444

52. Bagheri, R. - Polym. Int., 48, p.1257 (1999). http://dx.doi.org/10.1002/ (SICI) 1097-0126(199912)48:12<1257::AID-PI301>3.0.CO;2-Z

53. La Mantia, F. P. \& Valenza, A. - Polym. Degrad. Stab., 13, p.105 (1985). http://dx.doi.org/10.1016/0141-3910(85)90059-X

54. Singh, R. P.; Raj, R. A.; Prasad, A. V.; Sivaram, S.; Lacoste, J. \& Lemaire, J. - Polym Intl., 36, p.309 (1995). http://dx.doi.org/10.1002/ pi.1995.210360402

55. Edge, M.; Allen, N. S.; Wiles, R.; McDonald, W. \& Mortlock, S. V. - Polymer, 36, p.227 (1995). http://dx.doi.org/10.1016/00323861(95)91308-T

Enviado: 01/02/12

Reenviado: $23 / 03 / 12$

Aceito: $16 / 05 / 12$ 